synthesize the highly specific proteins which, when combined with hæm, impart to it the remarkable property of reversible oxygenation. This property, which hæmoglobin shares with only a few natural oxygen carriers, has no analogy among chemical compounds.

The root nodule hæmoglobin represents the first case of the occurrence of this pigment in plants, although other hæmatin compounds such as cytochrome peroxidase and catalase are known in plants. What is, however, more interesting is that neither the plant cells alone nor the symbiotic micro-organisms (Rhizobium) cultivated separately are capable of synthesizing hæmoglobin. It is only when the root cells are invaded by specific symbiotic micro-organisms and begin to proliferate that hæmoglobin is formed. Rhizobium not only induces growth and multiplication of cells, but also supplies these proliferating cells directly or indirectly with a factor necessary for synthesis of hæmoglobin.

For the plant material used in the present investigation we wish to thank Dr. H. Hunter, Mr. E. G. Thompson, Prof. E. J. Salisbury and Dr. Kenneth M. Smith. This work was assisted by a personal grant from the Medical Research Council to one of us (Y. L. W.).

${ }^{2}$ Pietz, J., Z. Bakt., (2), 99, 1 (1938).

${ }^{2}$ Kubo, H., Acta Phytochim., 11, 195 (1939).

${ }^{3}$ Burris, R. M., and Haas, E., J. Biol. Chem., 155, 227 (1944).

- Wilson, P. W., Ergeb. Enzymfor., 8, 13 (1939).

${ }^{5}$ Wilson, P. W., "The Biochemistry of Symbiotic Nitrogen. Fixation" (Madison: The University of Wisconsin Press, 1940).

\section{RUSSIAN RUBBER PLANTS}

$\mathrm{TN}$ recent years there has been a great deal of in. terest in the study of rubber-bearing plants that will grow in temperate and sub-temperate climates in connexion with the possibility of establishing sources of supply of natural rubber independent of the tropics. Russian workers have been the pioneers in this field, and it is in the U.S.S.R. that the most noteworthy developments have taken place. The published accounts of this work (mainly in Russian) are unfortunately difficult of access, especially at the present time. It is fitting, therefore, that a comprehensive summary (in English) should now have appeared, with special emphasis on what is so far known of the genetics of the plants concerned and what breeding work has so far been carried out with them*.

A brief history is given of the search for rubberbearing plants in the U.S.S.R. which first began during the War of 1914-18 and of the expeditions that have been arranged for the purpose. Since that time, several thousand species have been examined, and special methods evolved for detecting the presence of rubber both qualitatively and quantita. tively. Apart from latex-bearing plants, many species were found to contain rubber in the mesophyll tissue of the leaves, but successful extraction presented many difficulties. The most promising rubberbearing plants outside the tropics were found to be those containing coagulated rubber in the roots and underground stems. In these plants the rubber, often visible as strands, was found to be more easily separated from the surrounding tissue than was the

* Cultivation and Breeding of Russian Rubber-Bearing Plants. Imperial Bureaux of Plant Breeding and Genetics, Cambridge, and
Horticulture and Plantation Crops, East Malling, Fingland. 28, $6 d .6$ case where the rubber occurred in the leaves. Furthermore, it was found to have a markedly lower resin content.

The first plant of this class to show promise as a possible commercial source of rubber, if cultivated, was tau-saghyz (Scorzonera tau-saghyz), discovered in 1929 on the Kara-Tau mountains of Central Asia. Several forms or ecotypes of the plant are now known to exist. A good account of the plant is given, its growth characteristics and its behaviour under cultivation. Although possessing a good rubber content in the root, the plant proved susceptible to disease and difficult to cultivate satisfactorily in most areas. For this reason it gave way to other rubber-bearing species brought to light a few years later, which proved to be better subjects under cultivation, such as krim-saghyz (Taraxacum megalorrhyzon) and koksaghyz (Taraxacum kok-saghyz).

Both these plants are very similar to the ordinary dandelion in general appearance and possess large, rather fleshy roots in which the rubber is chiefly located. Kok-saghyz is the more hardy plant and may be cultivated over a much wider area of the U.S.S.R. than krim-saghyz. The latter occurs wild in the Crimea region and is liable to be killed in winter except in places where winter conditions are relatively mild. It is for this reason that interest is now centred mainly on kok-saghyz, and the area devoted to it is the largest of all the areas in which rubber-bearing plants are now grown. The plant is usually cultivated in districts where the annual rainfall is not less than $450-500 \mathrm{~mm}$. and thrives particularly in the central part of the U.S.S.R., as in the Orel and Ivanov territories and in the Ukraine and White Russia, also in irrigated lands in Central Asia. It has been grown as far north as the Kotlas region of the Archangel territory. The plant thrives and gives the best yields on low-lying alluvial land, especially good peaty and humus soils and in particular those that have been well manured. In White Russia, experiments have shown that on peaty soils larger yields of roots with higher rubber content have been obtained than has been found possible on mineral soils. For high yields of root, deep, fertile, friable soils rich in nutrients and with adequate moisture are necessary. Structureless soils, which rain turns into mud and which lack nutrients, or sandy soils, are regarded as unsuitable for kok-saghyz.

A good account is given of the methods adopted in the field cultivation of kok-saghyz from the sowing of the seed to the harvesting of the roots. As germination of the seeds is naturally poor or uneven, pretreatment or vernalization is often necessary. The seedlings are also somewhat delicate and slow-growing. They are easily choked or smothered by weeds in the early stages. For these reasons the crop is a more difficult one to raise than many field crops. Special machinery has had to be devised for dealing with the crop, particularly in sowing the seed, harvesting the roots and in the collection of seed, which is similar to that of the dandelion and dispersed by wind almost as soon as it is ripe.

Propagation by means of root fragments, which is possible with the plant if certain precautions are taken (as recommended by Lysenko), should offer interesting possibilities, but so far does not appear to have progressed beyond the experimental stage. Pieces of the root $1-2 \mathrm{~cm}$. long cut off in the early spring and allowed to callus in moist sand and planted in place of seed make much more rapid growth than seedlings, and when a fow days old 
resemble seedlings two months old. This simplifies weeding. Another obvious advantage is that highyielding individual plants may be rapidly propagated vegetatively in this way. A drawback of this method for large-scale or field planting, according to Mynbaevdel, is that the development of the main root is retarded.

Various insects are known to attack the koksaghyz plant in different stages of its development, and a good account of these is given. With regard to soil pests the chief of these in the more northerly regions is the wireworm. Cockchafer larvæ, which gnaw through the roots at various depths, may also be troublesome.

Genetical work that has been done on certain other rubber-yielding. plants in the U.S.S.R. in addition to the above is also reviewed. These include species of Asclepias, Apocynum, Solidago (golden rod), Scorzonera, Chrysothamnus, Parthenium (guayule) and Taraxacum. Each genus is treated in a separate section, and information is given under the headings of: $A$, Taxonomy and Distribution; $B$, Cytology and Reproduction ; $C$, Variation and Genetics ; and $D$, Breeding. Guayule and the species of Taraxacum have received most attention, as might be expected in view of the fact that they have shown most promise as rubber producers.

With regard to guayule the opinion is expressed that the breeding stocks in the U.S.S.R. and in the United States differ considerably in their potentialities and that the Russian are inferior to the American. This is not surprising when it is considered that the American breeders have had continuous access to wild material while the Russians have had to develop their strains from a single collection. The fact that the development of American varieties was monopolized by a private firm until recently (1942) has probably discouraged other breeders from investigating guayule. Improvement with guayule has been effected mainly by selection, rather than by hybridization, which is difficult. Strains yielding as much as 22 per cent rubber are now available, and there has been some improvement in plant-size but little in accelerating the growth-rate, plants being normally harvested in their third or fourth year.

Cytologists may be interested in the remarks regarding the genus Scorzonera, particularly tausaghyz, in connexion with which it is stated: "The diploid chromosome number is 14 and each chromosome has a distinctive morphology; they are all two-armed, 2 pairs having median centromeres and 5 pairs sub-terminal centromeres. It has been found that two races of the species exist, each distinguished by its own chromosomal morphology. In one race, satellites are present in three of the chromosome pairs, one of which is heterozygous for a second satellite. In the second race, satellites are completely absent. Examinations of the root tips of $S$. tau-saghyz have revealed rather a complicated picture of chimaeral polyploidy and aneuploidy. Triploid, tetraploid and hexaploid cells have been discovered both in the periblem and the plerome together with aneuploid cells with $15,16,18,19,20$ or 21 chromosomes. It is assumed that these various anomalous chromosome numbers arise by somatic non-disjunction or chromosome elimination. Trisomic cells have been observed in $S$. nervosa $(2 n=12)$ but not in other species of the genus. Chromosome numbers of some other species are as follows: $S$. hispanica $(2 n=14), S$. acanthoclada $(2 n=14)$ and $S$. tuberosa $(2 n=12)$.

"Meiotic behaviour in $S$. tau-saghyz is aberrant, and the following abnormalities have been observed: lagging chromosomes, adventitious nuclei, chromosome fragmentation, elimination of chromosomes from the spindle, polynucleate pollen and viable pollen with aneuploid chromosome numbers. It has been found however by Poddubnaja-Arnoldi, Steschina and Sosnovetz (1935) that gametogenesis is regular and that subsequent irregularities, which affect both the megaspores and the pollen grains, are due to the low temperature and high humidity of the plant's normal environment."

In the breeding of tau-saghyz the importance of selecting plants for vegetative vigour is stressed, for the mortality-rate of unselected plants may be very high and reach 100 per cent. The fact that tausaghyz is very susceptible to disease may, it is thought, be correlated with the scanty soil microflora in its native habitat. The advantages that might accrue from hybridizing tau-saghyz with the vegetable scorzonera (Scorzonera hispanica), which has been so long in cultivation and has vigour and a stout root, are emphasized.

Investigations of the cytology of kok-saghyz have been made by a number of workers. "There are eight pairs of chromosomes one of which has satellites attached. Meiosis is normal both in pollen grains and ovules and nearly 100 per cent pollen fertility is reported. The pollen is viable for five days, and fertilization takes place in 15-20 minutes, according to Poddubnaja-Arnoldi and Dianova and 30 minutes at $70^{\circ} \mathrm{F}$. according to Warmke. The embryo-sac usually develops from the chalazal megaspore. A high degree of self-sterility is usual although sc me 'end season fertility' is reported from America; the cause of this is obscure and the possible effects of temperature, light and the age of the plant have been suggested. Cross-pollination, which seldom occurs, naturally if insect visitors are excluded, produces $100 \%$ fertilization. The fertilized embryo develops normally although supernumerary eggs and sperms are formed quite frequently. It is possible that functional polyspermy may occur occasionally in the endosperm but only triploid nuclei have been observed up to the present. There is no evidence of apomixis in this species and it is regarded as extremely improbable."

Crosses have been made between kok-saghyz and about half a dozen other species of Taraxacum. "The hybrids are very highly sterile; normal meiosis occurs but is followed by subsequent degeneration of the gametes or the embryo. In the latter case, irregular nuclear fusions were observed in the early developmental stages. Koroleva (1939) managed to produce an $\mathrm{F}_{2}$ and $\mathrm{F}_{3}$ from the cross $T$. kok-saghyz $\times$ $T$. multiscaposum by back crossing with the former species."

It is interesting to note that seed of three of the rubber plants here dealt with (tau-, krim- and koksaghyz) was obtained from the U.S.S.R. a few years ago and small trials carried out at the Royal Botanic Gardens, Kew, and in various parts of the British Isles. Tau-saghyz appeared to be quite unsuited to the climate; but plants of kok-saghyz and krimsaghyz were raised successfully at several centres and good-quality rubber extracted, but only on a laboratory scale. With all these plants yields are very much inferior to those obtained with Hevea or plantation rubber. From the point of view of world economy they may be of comparatively little value, and it is only when self-sufficiency is desired that they become of general economic importance. 